\title{
Slip distribution of the 2011 off the Pacific coast of Tohoku Earthquake inferred from geodetic data
}

\author{
Takeo Ito, Kazuhiro Ozawa, Tsuyoshi Watanabe, and Takeshi Sagiya \\ Research Center for Seismology, Volcanology and Disaster Mitigation, Graduate School of Environmental Studies, Nagoya University
}

(Received April 12, 2011; Revised June 14, 2011; Accepted June 15, 2011; Online published September 27, 2011)

\begin{abstract}
We analyze geodetic observation data associated with the 2011 Tohoku Earthquake to estimate coseismic and early postseismic fault slip distribution on the Pacific plate interface. The maximum slip and the moment magnitude of the main shock are about $60 \mathrm{~m}$ and $M_{\mathrm{w}} 9.0$, respectively. The location of the main slip patch is complementary to the source region of large earthquakes at least for those which have occurred during the last 100 years, and the maximum slip was corresponded to a release of stress accumulation for about 700 years. Source regions of the 1936, 1938, and 1978 earthquakes are considered to have been re-ruptured in the 2011 main shock, where the slip amount was significantly smaller than the main patch.
\end{abstract}

Key words: Large coseismic slip distribution, geodetic data, geodetic inversion.

\section{Introduction}

A devastating earthquake occurred offshore the Tohoku region at 14:46 (JST) on March 11, 2011, causing tremendous damage by its strong shaking and tsunami. The social, as well as economic, impact of the earthquake was immense, with over 15,000 deaths and 10 trillion yen of damage directly attributed to the event. The earthquake was scaled as $M_{\mathrm{w}} 9.0$ by the Japan Meteorological Agency (JMA), which is the largest ever recorded in and around Japan in its history. It was also the world's first $M 9$ earthquake closely observed by dense seismological and geodetic networks. Appropriate analyses and interpretation of these observation data are indispensable for a better understanding of the nature of this huge event and to reduce future seismic as well as tsunami hazards.

It was unfortunate that the possibility of this $M 9$ event could not be predicted beforehand. However, the potential occurrence of a great earthquake had been suggested in the source region of the $M 9$ earthquake by geodetic, as well as geologic, studies. Several GPS studies have pointed to a significant amount of slip deficit in this area (Ito et al., 2000; Nishimura et al., 2004; Hashimoto et al., 2009). In addition, geological studies have suggested that large-scale tsunamis have repeatedly attacked the coastal area of the Sendai plain with an average interval of about 1,000 years (Minoura et al., 2001). It is of great importance to investigate the detailed slip distribution of the $M 9$ earthquake and to compare it with the GPS-based slip deficit and source regions of past earthquakes to understand the slip budget on the plate boundary and to infer the physical mechanism of this unexpectedly large event. For this purpose, we conduct an inversion analysis of on-land as well as offshore geodetic data to

Copyright (c) The Society of Geomagnetism and Earth, Planetary and Space Sciences (SGEPSS); The Seismological Society of Japan; The Volcanological Society of Japan; The Geodetic Society of Japan; The Japanese Society for Planetary Sciences; TERRAPUB.

doi:10.5047/eps.2011.06.023 estimate coseismic and early postseismic slip distributions.

\section{Observation}

Crustal deformation associated with the giant earthquake was recorded by the permanent nationwide dense GPS array GEONET, operated by the Geospatial Information Authority of Japan (GSI). It is the first time in the world's history that the occurrence and subsequent postseismic deformation process associated with a $M 9$ earthquake has been recorded by such a dense continuous GPS network. The whole northern Honshu island (about $500 \mathrm{~km}$ wide in the N-S direction) was displaced to the east by more than $1 \mathrm{~m}$, implying an occurrence of low-angle megathrust faulting on the interface of the subducting Pacific plate (see Fig. 1). In addition, we use horizontal displacement data from three seafloor geodetic sites just above the source region, which were measured by the Japan Coast Guard using the GPS/acoustic measurement (Fujita et al., 2006). One of the seafloor sites off the Miyagi prefecture moved about $24 \mathrm{~m}$ in the ESE direction associated with the earthquake (Sato et al., 2011).

Following the coseismic offsets, rapid postseismic transients and coseismic offsets of large aftershocks are detected over a wide area around the source region. Many GPS sites moved more than $5 \mathrm{~cm}$ during the first 8 hours after the main shock. The postseismic transients are considered to be mainly caused by afterslip and the largest aftershock ( $M$ 7.7) on the plate interface (see Fig. 4).

To infer slip distribution from geodetic observation data, we use preliminary GPS displacement data (version 0.3) for the March 11, 2011, earthquake provided by the Advanced Rapid Imaging and Analysis (ARIA) team at JPL and Caltech (The Advanced Rapid Imaging and Analysis, 2011). These coordinate solutions are obtained through a kinematic precise point-positioning analysis with GIPSYOASIS software, in which rapid orbit and clock products from JPL are used and the single-station bias-fixing method 


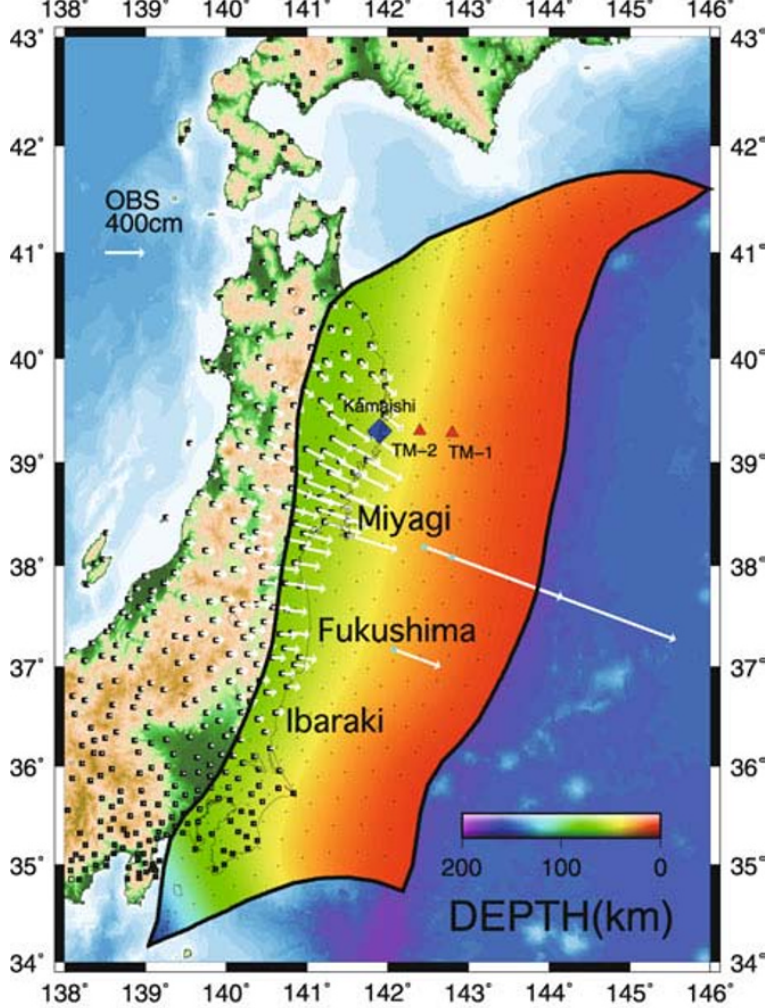

Fig. 1. Coseismic horizontal displacement vectors associated with the 2011 earthquake and configuration of the subducting Pacific plate used for analysis in this study. Dots inside the source region are knots of B-splines used for the slip distribution. Red triangles, blue and black squares show the ocean-bottom pressure gauges, the seafloor geodetic sites and GPS sites of GEONET, respectively.

is applied. Coseismic displacements of the main shock are obtained comparing the 5 min coordinate solutions at 14:40 and 14:55 JST. The period of coseismic observation is $15 \mathrm{~min}$, which is $6 \mathrm{~min}$ before and $9 \mathrm{~min}$ after the earthquake. For the early postseismic period, displacement data from 14:55 to 23:00 JST on March 11 are analyzed. The largest aftershock $(M 7.7,15: 15)$ occurred in the postseismic period off the Ibaraki prefecture.

\section{Method}

We conduct geodetic inversion analyses to estimate the coseismic and postseismic slip distribution on the curved plate interface. The configuration of the upper surface of the subducting Pacific plate is based on Slab 1.0 (Hayes and Wald, 2009; Hayes et al., 2009) which is based on a probabilistic non-linear fit to data from a combined catalog consisting of several independent data sets: historic earthquake catalogs, CMT solutions, active seismic profiles, global plate boundaries, bathymetry and sediment thickness information. We define a $900 \mathrm{~km} \times 400 \mathrm{~km}$ area as our model source region, wider than the actual source region as shown in Fig. 1. The slip distribution on the model source region is represented by a superposition of $35 \times 15$ bi-cubic B-spline functions, whose expansion coefficients are model parameters to be estimated from geodetic data (Yabuki and Matsu'ura, 1992). In our geodetic inversion, we apply the preconditioned conjugate gradient (PCG) method (Coleman and $\mathrm{Li}, 1996$ ), to the observational equation with a weak constraint on the slip direction $\left(\mathrm{N} 105^{\circ} \mathrm{E}\right)$ which reflects the relative plate motion. Since the PCG method is an iterative method, we need an initial estimate for the model parameters. No further constraints, such as smoothing, is introduced. We considered various cases and confirmed that the final solution does not depend on the initial values of the model parameters. Thus we conclude that our result is robust.

\section{Results and Discussion}

\subsection{Coseismic slip distribution}

The estimated coseismic slip distribution is shown in Fig. 2. Observed and calculated displacements are compared in Fig. 3. The largest slip is about $60 \mathrm{~m}$ centered at $\left(\mathrm{N} 37.6^{\circ}, \mathrm{E} 143.0^{\circ}\right)$ and the source region extends over about $200 \mathrm{~km}$ along the Japan Trench to the south of the epicenter. The seismic moment of the main shock is estimated to be $4.1 \times 10^{23} \mathrm{~N} \mathrm{~m}$, which is equivalent to $M_{\mathrm{w}}=9.0$, assuming a rigidity of $40 \mathrm{GPa}$.

The main rupture of the earthquake is located shallower than $20 \mathrm{~km}$, and surrounded by the source regions of the 1936, 1938 and 1978 events. The northern edge of the main source region is at the latitude $\mathrm{N} 38.8^{\circ}$. Maeda et al. (2011) suggested that ocean-bottom pressure-gauge records (TM-1 and TM-2 in Fig. 1) require no, or little, slip off Kamaishi, and that a large slip should occur far off the Miyagi prefecture. So the estimated slip distribution satisfies the constraints based on the ocean-bottom pressure-gauge records. On the other hand, the southern edge of the main slip region corresponds to one of the ocean-bottom geodetic sites off the Fukushima prefecture. Thus, the ocean-bottom geodetic observations contribute a lot to constrain the coseismic slip distribution. It should be noted that a fault slip of about 5-10 m occurred in the source region of past earthquakes with $M_{\mathrm{w}} 7 \sim 8$, suggesting that the 2011 earthquake ruptured those source regions again.

Previous studies estimated the distribution of the slip deficit rate by inverting three-dimensional GPS velocity data and have suggested that the plate boundary off the Miyagi prefecture is almost completely locked (Ito et al., 2000; Nishimura et al., 2004; Hashimoto et al., 2009). Although their slip deficit-rate estimation based on onland GPS data does not have sufficient resolving power for the offshore region, our coseismic slip distribution corresponds to their result quite well. A coseismic slip of $60 \mathrm{~m}$ corresponds to a release of accumulated stress of about 700 years, assuming the fully locking of the plate interface. The slip distribution suggests that historical seismicity over at least 700 years is necessary to understand the whole picture of the seismic cycle on this plate boundary. This is one of the important lessons from the 2011 earthquake.

\subsection{Early postseismic slip distribution}

The right panel of Fig. 2 shows the early postseismic slip distribution for 8 hours after the main shock. Figure 4 shows the observed and predicted displacements for the early postseismic period. The estimated afterslip distribution mainly reflects the coseismic slip of the largest aftershock. The southern end of the slip distribution of the largest aftershock corresponds to the northeastern limit of 


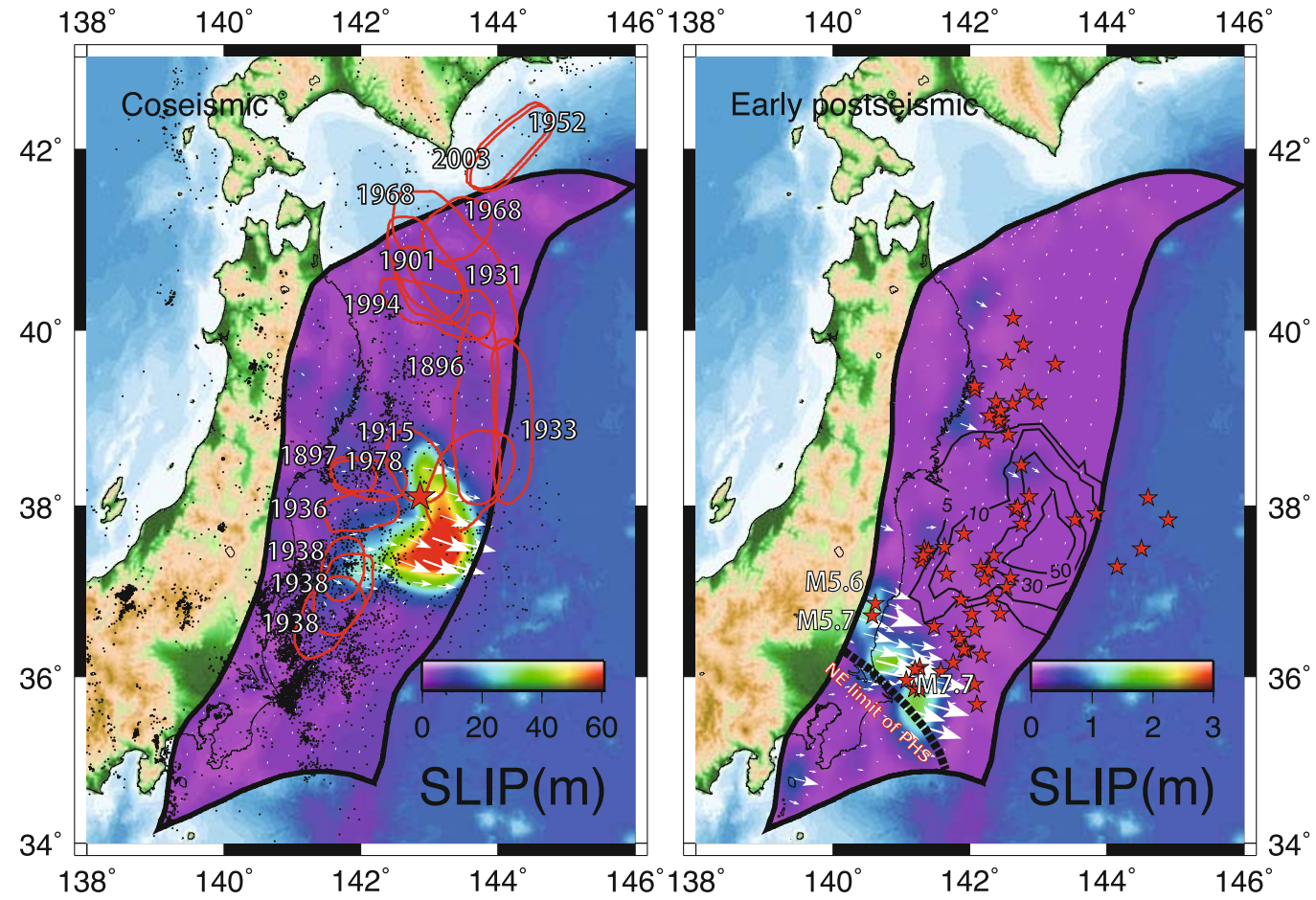

Fig. 2. Estimated coseismic (left) and postseismic (right) slip distribution. Colors and white arrows denote the absolute amount and direction of the fault slip, respectively. Red ellipses in the left panel are the estimated source regions of past earthquakes (The Headquarters for Earthquake Research Promotion, 1999). Red star and black dots are the hypocenter of the main shock and aftershocks determined by JMA. The contour lines in the right panel show the coseismic slip distribution, and the black broken line shows the northeastern end of the Philippine Sea plate. Red stars are aftershock epicenters lager than $M 5.5$ from 14:55 to 23:00 on 11 March.

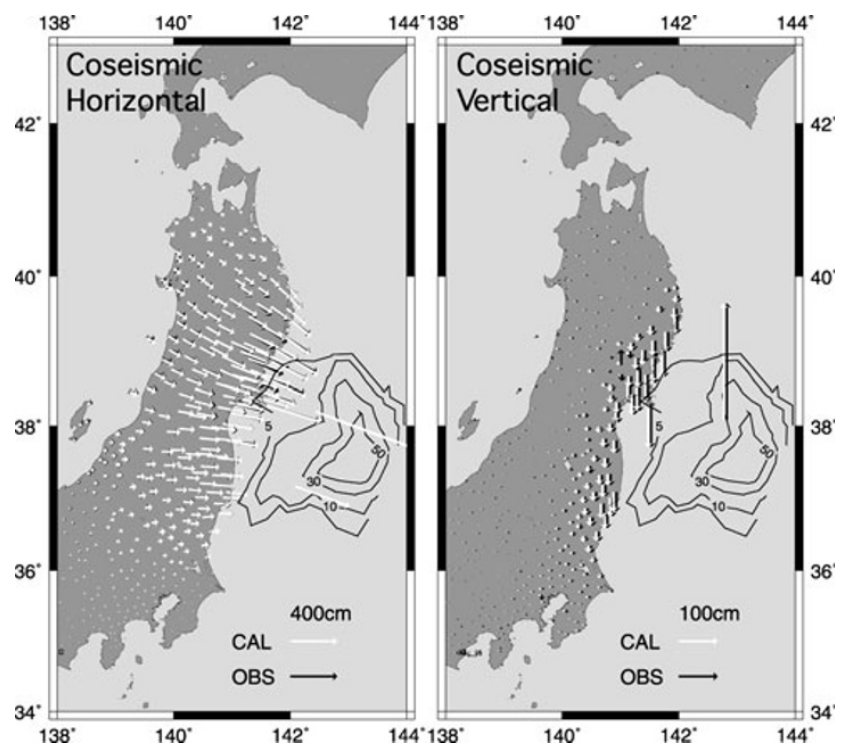

Fig. 3. Observed (black arrows) and predicted (white arrows) displacements due to the 2011 earthquake. The contour lines indicate the coseismic slip distribution.

the subducted Philippine Sea slab. Based on an analysis of a repeating earthquake, Uchida et al. (2009) suggested a dramatic contrast in the interplate coupling on the Pacific plate interface across the northern end of the Philippine Sea slab. They estimated stronger coupling on the northern side and the extent of the rupture of the largest aftershock is limited in this strongly-coupled region.

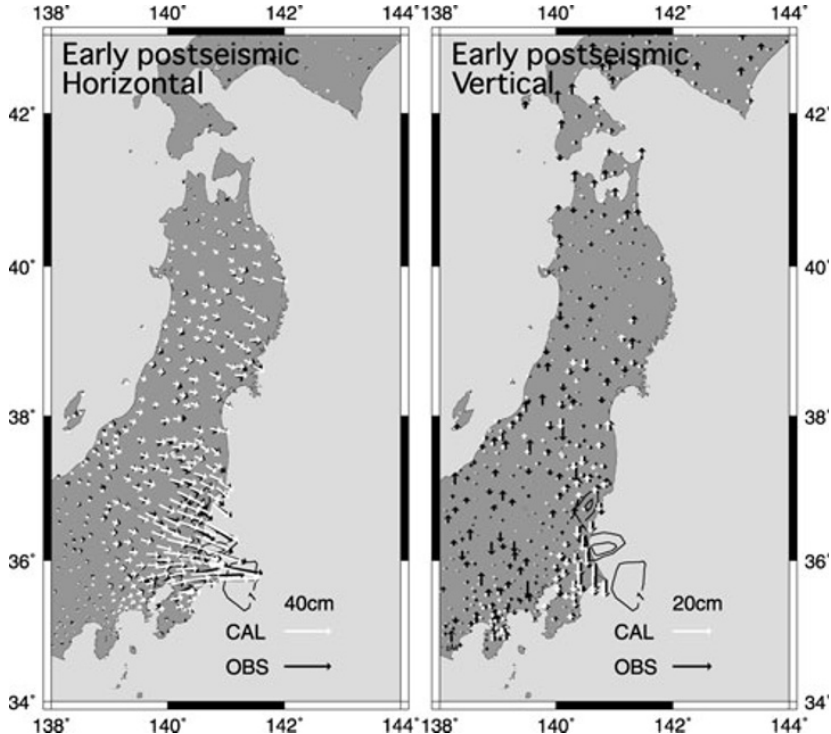

Fig. 4. Observed (black arrows) and predicted (white arrows) crustal deformation of the early postseismic period, which is from 14:55 to 23:00 (JST) on 11 March. The contour lines indicate the postseismic slip distribution.

The postseismic slip distribution also shows a large slip patch at the deeper end of the model source region. Probably, this can be attributed to shallow crustal aftershocks (M 5.6 and $M$ 5.7) in the Ibaraki prefecture, since these earthquakes seem too small to explain the observed deformation signal. Some large seismic events might occur in 
the shallow crust, leading to the anomalously active normal faulting activities in this region. A more detailed analysis of the geodetic data is necessary to investigate such a possibility.

\section{Summary}

We have estimated co- and post- seismic slip distributions of the 2011 off the Pacific coast of Tohoku Earthquake. The estimated moment magnitude $M_{\mathrm{w}}=9.0$ and the maximum slip of the main shock is about $60 \mathrm{~m}$. The earthquake is considered to have released tectonic stress accumulated over 700 years.

Acknowledgments. The authors thank S. Miyazaki and an anonymous reviewer for helpful comments. The figures were prepared using Generic Mapping Tools (Wessel and Smith, 1995). We used the preliminary GPS early displacement data (version 0.3 ) provided by the ARIA team at JPL and Caltech.

\section{References}

Coleman, T. F. and Y. Li, A reflective newton method for minimizing a quadratic function subject to bounds on some of the variables, SIAM J. Opt., 6(4), 1040-1058, 1996.

Fujita, M., T. Ishikawa, M. Mochizuki, M. Sato, S. Toyama, M. Katayama, K. Kawai, Y. Matsumoto, T. Yabuki, A. Asada, and O. L. Colombo, GPS/acoustic seafloor geodetic observation: method of data analysis and its application, Earth Planets Space, 58(3), 265-275, 2006.

Hashimoto, C., A. Noda, T. Sagiya, and M. Matsu'ura, Interplate seismogenic zones along the Kuril-Japan trench inferred from GPS data inversion, Nature Geosci., 2(2), 141-144, 2009.

Hayes, G. P. and D. J. Wald, Developing framework to constrain the geometry of the seismic rupture plane of subduction interface a priori-a probabilistic approach, Geophys. J. Int., 176, 951-964, 2009.

Hayes, G. P., D. J. Wald, and K. Keranen, Advancing techniques to constrain the geometry of the seismic rupture plane on subduction interfaces a priori-higher order functional fits, Geochem. Geophys. Geosyst., doi:10.1029/2009GC002633, 2009.
Ito, T., S. Yoshioka, and S. Miyazaki, Interplate coupling in northeast japan deduced from inversion analysis of GPS data, Earth Planet. Sci. Lett., 176, 117-130, 2000.

Maeda, T., T. Furumura, S. Sakai, and M. Shinohara, Significant tsunami observed at ocean-bottom pressure gauges during the 2011 off the $\mathrm{Pa}$ cific coast of Tohoku Earthquake, Earth Planets Space, 63, this issue, 803-808, 2011.

Minoura, K., F. Imamuraand, D. Sugawara, Y. Kono, and T. Iwashita, The 869 Jogan tsunami deposit and recurrence interval of large-scale tsunami on the pacific coast of northeast japan, J. Nat. Disast. Sci., 23(2), 83-88, 2001.

Nishimura, T., T. Hirasawa, S. Miyazaki, T. Sagiya, T. Tada, S. Miura and K. Tanaka, Temporal change of interplate coupling in northeastern japan during 1995-2002 estimated from continuous GPS observations, Geophys. J. Int., 157, 901-916, 2004.

Sato, M., T. Ishikawa, N. Ujihara, S. Yoshida, M. Fujita, M. Mochizuki, and A. Asada, Displacement above the hypocenter of the 2011 Tohokuoki earthquake, Science, doi:10.1126/science.1207401, 2011.

The Advanced Rapid Imaging and Analysis, Preliminary GPS early postseismic displacement data (version 0.3) for march 11, 2011 M9 Japanese earthquake, ftp://sideshow.jpl.nasa.gov/pub/usrs/ARIA/, 2011.

The Headquarters for Earthquake Research Promotion, Seismic Activity of Japan-Character of Each Region from a View Point of Disaster Earthquake —, Jitsugyo-koho Co., Ltd., 1999 (in Japanese).

Uchida, N., J. Nakajima, A. Hasegawa, and T. Matsuzawa, What controls interplate coupling?: Evidence for abrupt change in coupling across a border between two overlying plates in the NE japan subduction zone, Earth Planet. Sci. Lett., 283, 111-121, doi:10.1016/j.epsl.2009.04.003, 2009.

Wessel, P. and W. H. F. Smith, New version of the Generic Mapping Tools released, Eos Trans. AGU, 76, 329, 1995.

Yabuki, T. and M. Matsu'ura, Geodetic data inversion using a bayesian information criterion for spatial distribution of fault slip, Geophys. $J$. Int., 109, 363-375, 1992.

T. Ito (e-mail: takeo_ito@nagoya-u.jp), K. Ozawa, T. Watanabe, and T. Sagiya 